\title{
Effects of partial substitution of dietary fish oil with blends of vegetable oils, on blood leucocyte fatty acid compositions, immune function and histology in European sea bass (Dicentrarchus labrax L.)
}

\author{
Gabriel Mourente ${ }^{1}$, Joanne E. Good ${ }^{2} \dagger$, Kim D. Thompson ${ }^{2}$ and J. Gordon Bell ${ }^{2 *}$ \\ ${ }^{1}$ Departamento de Biología, Facultad de Ciencias del Mar y Ambientales, Universidad de Cádiz, E-11510 Puerto Real (Cádiz), Spain \\ ${ }^{2}$ Institute of Aquaculture, University of Stirling, Stirling FK9 4LA, UK \\ (Received 27 September 2006 - Revised 9 March 2007 - Accepted 12 March 2007)
}

Within a decade or so insufficient fish oil (FO) will be available to meet the requirements for aquaculture growth. Consequently, alternative sources are being investigated to reduce reliance on wild fish as a source of FO. Vegetable oils (VO) are a feasible alternative to FO. However, it is important to establish that alternative dietary lipids are not only supplied in the correct quantities and balance for optimal growth, but can maintain immune function and prevent infection, since it is known that the nutritional state of the fish can influence their immune function and disease resistance. A way of maintaining immune function, while replacing dietary FO, is by using a blend of VO rather than a single oil. In this study, juvenile European sea bass (Dicentrarchus labrax) were fed diets with a $60 \%$ substitution of FO with a blend of rapeseed, linseed and palm oils. Two oil blends were used to achieve a fatty acid composition similar to FO, in terms of energy content, and provide a similar balance of SFA, MUFA and PUFA. Fish were fed the diets for 64 weeks, after which time growth and fatty acid compositions of liver and blood leucocytes were monitored. The impact of the dietary blends on selected innate immune responses and histopathology were also assessed, together with levels of plasma prostaglandin $\mathrm{E}_{2}$. The results suggest that potential exists for replacing FO with a VO blend in farmed sea bass feeds without compromising growth, non-specific immune function or histology.

European sea bass: Vegetable oils: Fatty acid compositions: Immune function: Histology

Global catches from the feed-grade fisheries that provide fish oil (FO) and fish meal for aquafeed formulations have reached their sustainable limits ${ }^{1}$ and it is likely that within a decade or so there may be insufficient FO to meet the quantities required for current aquaculture growth ${ }^{2}$. Consequently, there has been considerable interest in introducing sustainable alternatives to fish meal and FO that reduce reliance on marine raw materials ${ }^{3,4}$. A number of recent studies suggest that dietary vegetable oil (VO) inclusion does not result in reduced growth performance or feed conversion in Atlantic salmon (Salmo salar) ${ }^{5,6}$, rainbow trout (Oncorhynchus mykiss) ${ }^{7}$, gilthead sea bream (Sparus aurata $^{8}$ or European sea bass (Dicentrarchus labrax) ${ }^{9}$. However, at levels above 50\% VO inclusion, significant accumulation of fatty acids derived from $\mathrm{VO}$, especially $18: 2 n-6$, and reduction of EPA $(20: 5 n-3)$ and DHA $(22: 6 n-3)$ occurs in fish tissues ${ }^{5,6,8,9}$.

The nutritional status of an organism, including fish, is known to influence immune functions ${ }^{10}$ and the overall resistance of an organism to disease is therefore dependent on their nutritional status. The first review suggesting that fatty acids might be important in immune function was by Meade \&
Mertin $^{11}$ and more recent reviews have confirmed the importance of PUFA, of both the $n-6$ and $n-3$ series, as modulators of immune function ${ }^{12,13}$. Fatty acids are incorporated into the plasma membrane from dietary lipids, so that the fatty acid composition of cellular membranes reflects the composition of dietary lipids ${ }^{14}$. In fish, dietary fatty acids and tissue fatty acid compositions are closely correlated ${ }^{15}$ and changes in the dietary $n-3 / n-6$ ratio can influence the compositions of fish immune cells, including blood leucocytes ${ }^{16-18}$.

Fatty acids have diverse roles in all cells. They are important as a source of energy, as structural components of cell membranes and as signalling molecules. In mammalian studies, dietary fatty acids may be able to modulate the immune system through several mechanisms including reduction of lymphocyte proliferation, cytokine synthesis and phagocytic activity, and also by modification of natural killer cell activity ${ }^{19}$. The main event in the modulation of immune function may be associated with changes in the cell membrane due to dietary fatty acid manipulation. It is likely that modulation of the overall immune system occurs as a result of alterations in membrane fluidity, lipid peroxidation, eicosanoid production or regulation of gene expression ${ }^{20}$.

Abbreviations: ARA, arachidonic acid; FO, fish oil; LO, linseed oil; PBL, peripheral blood leucocytes; PGE 2 , prostaglandin $\mathrm{E}_{2}$; PO, palm oil; RO, rapeseed oil; VO, vegetable oils.

$\dagger$ Present address: Bio-Stat Ltd, Bio-Stat House, Pepper Road, Hazel Grove, Stockport SK7 5BW, UK.

* Corresponding author: Dr J. Gordon Bell, fax +44(0)1786 472133, email g.j.bell@stir.ac.uk 
In the present study, triplicate groups of juvenile European sea bass were fed diets that were based on $60 \%$ substitution of FO with a blend of rapeseed (RO), linseed (LO) and palm oils (PO). The level of $60 \%$ substitution was chosen as this was the maximum level of VO inclusion that could be tolerated in marine fish without loss of growth performance ${ }^{8,9}$. The oils were blended in two different formulations to achieve a fatty acid composition as similar to anchovy oil as possible, in terms of energy content, and provide a similar balance of SFA, MUFA and PUFA to that found in FO, but without highly unsaturated fatty acids. The fish were fed the diets for 64 weeks starting at an initial weight of approximately $5 \mathrm{~g}$. Growth parameters and the fatty acid compositions of liver and peripheral blood leucocytes (PBL) were monitored after 64 weeks. The impact of the dietary blends on selected aspects of the innate immune response (haematological parameters, serum lysozyme activity and macrophage respiratory burst activity) and histopathology were also assessed in the experimental fish at this time, together with levels of plasma prostaglandin $\mathrm{E}_{2}\left(\mathrm{PGE}_{2}\right)$.

\section{Materials and methods \\ Experimental fish and diets}

European sea bass (Dicentrarchus labrax L.), 7.9 (SD 0.5) cm in length and 5.2 (SD 1.0) $\mathrm{g}$ in weight, were purchased from MARESA (Huelva, Spain) and transported to the marine aquarium facility at the University of Cádiz, Faculty of Marine and Environmental Sciences, Puerto Real (Cádiz). On arrival the fish were placed in nine 5000-litre rectangular tanks at 600 fish per tank (approximately $0.6 \mathrm{~kg} / \mathrm{m}^{3}$ ), with salinity of $39 \%$, temperature of $20^{\circ} \mathrm{C}$ and saturated with oxygen. Following 2 weeks acclimation (July 2002), triplicate groups of fish were fed to satiation, using mechanical belt automatic feeders with three isoenergetic and isonitrogenous experimental diets formulated to provide a constant lipid content of approximately $22 \%$ (Nutreco ARC, Stavanger, Norway). The diets contained approximately $47 \%$ protein, primarily provided by fish meal, and $21.4,24.1$ and $21.5 \%$ lipid for diets of pellet size 2,3 and $5 \mathrm{~mm}$, respectively. Two experimental diets contained $60 \%$ of three VO, LO, PO and RO, blended to provide a balance of SFA, MUFA and PUFA similar to that found in FO, but without highly unsaturated fatty acids. The control diet contained anchovy oil and the added oil combinations for the three experimental diets were: Diet A: $100 \%$ anchovy oil (control); Diet B: $40 \%$ anchovy oil, $35 \%$ LO, $15 \%$ PO and 10\% RO; Diet C: $40 \%$ anchovy oil, $24 \% \mathrm{LO}, 12 \% \mathrm{PO}$ and $24 \% \mathrm{RO}$. The formulation and proximate compositions of the experimental diets are shown in Table 1, while diet total lipid content and fatty acid compositions are shown in Table 2.

\section{Sample collection and biometric measurements}

After feeding the experimental diets for 64 weeks, thirty fish per tank (i.e. ninety fish per replicate) were sampled for length and live mass, and Fulton's condition factor $(K)$ and specific growth rates were recorded. Ten fish per replicate (i.e. thirty fish per dietary treatment) were sampled and liver (live and dry mass), hepatosomatic index and flesh (live and
Table 1. Formulation and proximate composition of experimental diets ( $5 \mathrm{~mm}$ pellet size; $\mathrm{g} / \mathrm{kg}$ feed)

\begin{tabular}{|c|c|c|c|}
\hline & Diet $A$ & Diet B & Diet C \\
\hline \multicolumn{4}{|l|}{ Components ${ }^{*}$} \\
\hline Fish meal & $400 \cdot 0$ & $400 \cdot 0$ & $400 \cdot 0$ \\
\hline Maize gluten & $262 \cdot 7$ & $262 \cdot 7$ & $262 \cdot 7$ \\
\hline Wheat & $152 \cdot 3$ & $152 \cdot 3$ & $152 \cdot 3$ \\
\hline Oil & $160 \cdot 0$ & $160 \cdot 0$ & $160 \cdot 0$ \\
\hline Premixes† & $25 \cdot 0$ & $25 \cdot 0$ & $25 \cdot 0$ \\
\hline \multicolumn{4}{|c|}{ Composition (\%) of added oil } \\
\hline Anchovy oil¥ & 100 & 40 & 40 \\
\hline Rapeseed oil§ & 0 & 10 & 24 \\
\hline Linseed oil|| & 0 & 35 & 24 \\
\hline Palm oilø & 0 & 15 & 12 \\
\hline \multicolumn{4}{|c|}{ Proximate composition (\%) } \\
\hline Crude protein & $47 \cdot 8$ & $46 \cdot 2$ & $47 \cdot 8$ \\
\hline Crude lipid & $22 \cdot 2$ & $24 \cdot 3$ & $21 \cdot 2$ \\
\hline Carbohydrate & $13 \cdot 1$ & $13 \cdot 3$ & $15 \cdot 4$ \\
\hline Ash & $6 \cdot 7$ & $6 \cdot 3$ & $6 \cdot 2$ \\
\hline Moisture & $10 \cdot 2$ & $10 \cdot 9$ & 9.4 \\
\hline
\end{tabular}

${ }^{*}$ Fish meal from Scandinavian LT-fish meal (Nordsildmel, Norway); maize gluten from Cargill (Staley, NC, USA); wheat from Statkorn (Oslo, Norway).

† Vitamin and mineral premix added exceed National Research Council (1993) recommendations.

$\ddagger$ Anchovy oil (Denofa, Fredrikstad, Norway) supplemented with 200 ppm butylated hydroxytoluene.

$\S$ Crude rapeseed oil (Oelmühle, Hamburg, Germany), no antioxidant added.

\|Crude E.C.C. linseed oil (N.V. Oliefabriek, Lictervelde, Belgium) supplemented with 500 ppm Ronoxan A (Roche, Basel, Switzerland).

I Crude palm oil (Denofa, Norway).

Table 2. Total lipid content (\% of dry mass) and fatty acid composition (weight \% of total fatty acids) of the experimental diets ( $5 \mathrm{~mm}$ pellet size) (Mean values and standard deviations for three determinations)

\begin{tabular}{|c|c|c|c|c|c|c|}
\hline & \multicolumn{2}{|c|}{ Diet A } & \multicolumn{2}{|c|}{ Diet B } & \multicolumn{2}{|c|}{ Diet C } \\
\hline & Mean & SD & Mean & SD & Mean & SD \\
\hline Total lipid (\%) & $20 \cdot 2$ & $3 \cdot 1$ & $21 \cdot 2$ & $4 \cdot 3$ & $21 \cdot 1$ & $2 \cdot 8$ \\
\hline \multicolumn{7}{|l|}{ Fatty acid (\%) } \\
\hline $14: 0$ & $4 \cdot 3^{a}$ & 0.1 & $1.9^{b}$ & 0.2 & $1.9^{b}$ & 0.2 \\
\hline $15: 0$ & 0.5 & $0.0^{*}$ & 0.3 & 0.1 & 0.6 & 0.0 \\
\hline $16: 0$ & $14 \cdot 0^{a}$ & 0.2 & $13 \cdot 3^{b}$ & 0.1 & $12 \cdot 5^{c}$ & 0.1 \\
\hline $18: 0$ & $3 \cdot 0^{a}$ & 0.1 & $3 \cdot 1^{a}$ & 0.1 & $2 \cdot 7^{\mathrm{b}}$ & 0.0 \\
\hline Total SFA† & $22 \cdot 9^{a}$ & 0.1 & $19 \cdot 5^{\mathrm{b}}$ & 0.2 & $18 \cdot 6^{c}$ & 0.3 \\
\hline $16: 1 n-9 / n-7$ & $13 \cdot 6^{a}$ & 0.6 & $11 \cdot 4^{\mathrm{b}}$ & 1.9 & $10 \cdot 2^{b}$ & 0.3 \\
\hline $18: 1 n-9$ & $9 \cdot 4^{\mathrm{C}}$ & 0.2 & $16 \cdot 9^{b}$ & 0.4 & $21 \cdot 6^{a}$ & 0.4 \\
\hline $18: 1 n-7$ & $2 \cdot 2^{a}$ & 0.1 & $1 \cdot 8^{\mathrm{C}}$ & 0.0 & $2 \cdot 0^{\mathrm{b}}$ & 0.0 \\
\hline $20: 1 n-9$ & $2 \cdot 3^{a}$ & 0.0 & $1.9^{c}$ & 0.0 & $2 \cdot 0^{b}$ & 0.0 \\
\hline $22: 1 n-11$ & $2 \cdot 0^{a}$ & 0.1 & $1 \cdot 7^{\mathrm{b}}$ & 0.1 & $1 \cdot 7^{\mathrm{b}}$ & 0.0 \\
\hline Total MUFA & $30 \cdot 7^{c}$ & 0.7 & $34 \cdot 6^{b}$ & 1.5 & $38 \cdot 1^{a}$ & 0.4 \\
\hline $18: 2 n-6$ & $4 \cdot 9^{C}$ & 0.0 & $9 \cdot 0^{\mathrm{b}}$ & 0.7 & $10 \cdot 4^{a}$ & 0.2 \\
\hline $20: 4 n-6$ & $0.6^{\mathrm{a}}$ & 0.0 & $0 \cdot 3^{\mathrm{b}}$ & 0.0 & $0 \cdot 3^{b}$ & 0.0 \\
\hline Total $n-6$ & $7 \cdot 4^{\mathrm{c}}$ & 0.1 & $10 \cdot 7^{b}$ & 0.5 & $11 \cdot 8^{a}$ & 0.2 \\
\hline $18: 3 n-3$ & $1 \cdot 5^{\mathrm{c}}$ & 0.0 & $12 \cdot 3^{a}$ & 0.7 & $10 \cdot 3^{b}$ & 0.3 \\
\hline $18: 4 n-3$ & $2 \cdot 0^{\mathrm{a}}$ & 0.0 & $1 \cdot 1^{\mathrm{b}}$ & 0.1 & $1 \cdot 0^{\mathrm{b}}$ & 0.0 \\
\hline $20: 4 n-3$ & $0.5^{\mathrm{a}}$ & 0.0 & $0.3^{b}$ & 0.0 & $0 \cdot 3^{\mathrm{b}}$ & 0.0 \\
\hline $20: 5 n-3$ & $9 \cdot 8^{a}$ & 0.1 & $5 \cdot 3^{b}$ & 0.3 & $5 \cdot 2^{b}$ & 0.1 \\
\hline $22: 5 n-3$ & $1 \cdot 2^{\mathrm{a}}$ & 0.0 & $0.7^{b}$ & 0.0 & $0.6^{\mathrm{b}}$ & 0.0 \\
\hline $22: 6 n-3$ & $11 \cdot 0^{\mathrm{a}}$ & 0.3 & $6 \cdot 3^{b}$ & 0.5 & $6 \cdot 2^{\mathrm{b}}$ & 0.1 \\
\hline Total $n-3$ & $27 \cdot 9^{a}$ & 0.5 & $27 \cdot 0^{\mathrm{ab}}$ & $1 \cdot 7$ & $24 \cdot 5^{\mathrm{b}}$ & 0.6 \\
\hline Total PUFA§ & 35.4 & 0.6 & $37 \cdot 8$ & $2 \cdot 1$ & $36 \cdot 3$ & 0.9 \\
\hline$n-3 / n-6$ & $3 \cdot 8$ & $0.5^{a}$ & $2 \cdot 5^{\mathrm{b}}$ & 0.5 & $2 \cdot 1^{b}$ & 0.5 \\
\hline
\end{tabular}

a,b,c Mean values within a row with unlike superscript letters were significantly different $(P<0.05)$.

* Standard deviation of 0.0 implies SD $<0.05$.

†Includes 20: 0 and 22: 0 .

$\ddagger$ Includes 18:1n-11, 20:1n-11, 20:1n-7 22:1n-9 and $24: 1$.

$\S$ Includes $16: 2,16: 3,16: 4,20: 2 n-6,20: 3 n-6$ and $22: 5 n-6$. 
dry mass) were recorded. Liver samples for fatty acid analyses were dissected from four fish per replicate (i.e. twelve fish per dietary treatment) and immediately frozen in liquid nitrogen and stored at $-80^{\circ} \mathrm{C}$ until analysed. Blood for eicosanoid analysis $(2 \mathrm{ml})$ was collected in heparinised syringes from six fish per dietary treatment, and centrifuged at $12000 \mathrm{~g}$ for 2 min. The plasma was collected and acidified by the addition of $2 \mathrm{M}$-formic acid $(50 \mu \mathrm{l} / \mathrm{ml})$ and immediately frozen in liquid nitrogen for eicosanoid analysis. Heparinised blood samples were also used for haematological analyses. Live mass of the liver was determined by blotting the tissue on filter paper before weighing, and dry mass was determined after heating to $60^{\circ} \mathrm{C}$ for $24 \mathrm{~h}$ and cooling under vacuum before weighing. Hepatosomatic index was calculated as liver live mass $\times 100 /$ fish live mass. Fulton's condition factor $(K)=\left(W / L^{3}\right) \times 100$, where $W$ is the fish weight $(\mathrm{g})$ and $L$ is the total length $(\mathrm{cm})$. Specific growth rate was calculated as $\%$ weight gain $/ \mathrm{d}^{21}$. Non-specific mortality was measured at the end of the experiment and expressed as a percentage of surviving fish.

\section{Proximate analysis of diets}

Moisture content was determined by thermal drying to constant weight in an oven at $110^{\circ} \mathrm{C}$ for $24 \mathrm{~h}$. For the total protein content, the micro-Kjeldahl analysis method was followed, using a Digestion system 40-1006 Heating Unit (Foss, Warrington, UK) and a Kjeltec Auto 1030 Analyzer (Foss). To convert total nitrogen to total protein content, as a percentage of dry weight, the factor 6.25 (100/16) was used. Crude fat was determined by acid hydrolysis with a Soxtec System 1047 Hydrolyzing Unit, followed by Soxhlet extraction using a Soxtec System HT6 (Foss). Ash content as a percentage of dry weight was determined by dry ashing in porcelain crucibles in a muffle furnace, at $600^{\circ} \mathrm{C}$ overnight $^{22}$.

\section{Lipid analysis}

Total lipid in samples was extracted after homogenisation, using an Ultraturrax tissue disrupter (Fisher Scientific, Loughborough, UK), in ten volumes of chloroform-methanol $(2: 1, \mathrm{v} / \mathrm{v})$ containing $0.01 \%$ butylated hydroxytoluene as antioxidant, basically according to Folch et al. $^{23}$ and essentially as described by Christie ${ }^{24}$.

Fatty acid methyl esters were prepared from aliquots of total lipids by acid-catalysed transmethylation for $16 \mathrm{~h}$ at $50^{\circ} \mathrm{C}$, using tricosanoic acid $(23: 0)$ as internal standard ${ }^{24}$. Fatty acid methyl esters were extracted and purified as described previously $^{25}$ and were separated using a Hewlett-Packard 5890A Series II gas chromatograph (Hewlett-Packard, Barcelona, Spain) equipped with a chemically bonded (PEG) Supelcowax-10 fused silica wall coated capillary column ( $30 \mathrm{~m} \times 0.32 \mathrm{~mm}$ i.d.; Supelco Inc., Bellefonte, PA, USA), using an 'on column' injection system and flame ionisation detection. Hydrogen was used as the carrier gas with an oven thermal gradient from an initial $50^{\circ} \mathrm{C}$ to $180^{\circ} \mathrm{C}$ at $25^{\circ} \mathrm{C} / \mathrm{min}$ and then to a final temperature of $235^{\circ} \mathrm{C}$ at $3^{\circ} \mathrm{C} /$ min, with the final temperature maintained for $10 \mathrm{~min}$. Individual fatty acid methyl esters were identified by comparison with known standards and quantified by means of a direct-linked PC and Hewlett-Packard ChemStation software.
Extraction and measurement of prostaglandin $E_{2}$ concentrations in plasma

The frozen acidified plasma samples were thawed and centrifuged at $12000 \mathrm{~g}$ for $2 \mathrm{~min}$ to remove any precipitate. The supernatants were extracted using octadecyl silyl (C18) 'Sep-Pak' mini-columns (Millipore) as described in detail by Bell et al. ${ }^{26}$. C18 'Sep-Pak' mini columns were pre-washed with $5 \mathrm{ml}$ methanol and $10 \mathrm{ml}$ distilled water, plasma samples were charged on the mini-column, washed with a further $10 \mathrm{ml}$ distilled water and the eicosanoids eluted in $5 \mathrm{ml}$ ethyl acetate. Samples were dried under nitrogen and redissolved in immunoassay buffer. Quantification of PGE was performed using enzyme immunoassay kits, according to the manufacturers protocol (SPI-Bio, Massy, France).

\section{Measurement of cellular immune parameters}

Eight fish per dietary treatment were sampled after 64 weeks of feeding the experimental diets. Fish were anaesthetised with a lethal dose of tricaine methanesulphonate (MS-222, Sigma, Poole, UK). Blood samples were collected in heparinised vacuum tubes (vacutainer; Becton Dickinson Vacutainer System, Oxford, UK) from the caudal vein.

\section{Preparation of peripheral blood leucocytes}

PBL were isolated from blood from three fish per dietary treatment using the lymphocyte separation medium, Histopaque ${ }^{\circledR}$ (Sigma) and density gradient centrifugation. Blood $(1 \mathrm{ml})$ was diluted with L-15 medium $(4 \mathrm{ml})$ and $3 \mathrm{ml}$ of the diluted blood was layered on to $4 \mathrm{ml}$ Histopaque ${ }^{\circledR}$ and centrifuged at $400 \mathrm{~g}$ for $45 \mathrm{~min}$. The leucocyte band was collected using a Pasteur pipette and stored in $1 \mathrm{ml}$ chloroform-methanol $(2: 1, \mathrm{v} / \mathrm{v})$ at $-20^{\circ} \mathrm{C}$ until required for lipid extraction. If erythrocyte contamination of PBL was considered to be excessive $(>2 \%)$ then the PBL fraction was centrifuged again on $4 \mathrm{ml}$ fresh Histopaque ${ }^{\circledR}$.

\section{Haematology}

Blood was used immediately for haematological studies. Haematocrit values were obtained using heparinised microhaematocrit tubes and centrifuging at $12000 \mathrm{~g}$ for $4 \mathrm{~min}$ (Microcentrifuge MH2; Sarstedt Ltd, Leicester, UK). Total erythrocyte and total leucocyte counts (including thrombocytes) were made using PBS for dilution and an improved Neubauer haemocytometer (Hawksley, Lancing, UK).

\section{Serum lysozyme activity}

An aliquot of blood was allowed to clot at $4^{\circ} \mathrm{C}$ overnight. Serum was separated by centrifugation at $4000 \mathrm{~g}$ for $15 \mathrm{~min}$ and stored at $-20^{\circ} \mathrm{C}$ until analysis. Serum lysozyme activity was assayed by a turbidimetric assay which measures the lytic activity of the sea bass serum against Microccocus lysodeikticus. $^{27,28}$ A suspension of $190 \mu$ l of bacteria (Micrococcus lysodeikticus; Sigma) and $10 \mu \mathrm{l}$ of serum sample was measured spectrophotometrically at $540 \mathrm{~nm}$ in five replicate wells per serum sample after 1 and $5 \mathrm{~min}$ at $25^{\circ} \mathrm{C}$, using a Dynatech MRX 1.2 ELISA reader (Dynatech Laboratories 
Ltd, Billingshurst, West Sussex, UK). The bacterial suspension $(0.2 \mathrm{mg} / \mathrm{ml})$ was prepared in sodium phosphate buffer $(0.04 \mathrm{M}, \mathrm{pH} 5.8)$. The results are given as units $(\mathrm{U}) / \mathrm{ml}$ per min $(1 \mathrm{U}=$ the amount of sample causing a decrease in absorbance of 0.001 per min).

\section{Macrophage respiratory burst activity}

The reduction of nitroblue tetrazolium salt to formazan by oxygen radicals produced by head kidney macrophages during respiratory burst activity was measured spectrophotometrically as described by Chung \& Secombes ${ }^{29}$. Isolation and culture of head kidney macrophages were performed as described by Secombes ${ }^{30}$, however, instead of placing the cell suspensions on Percoll to isolate the macrophages, $200 \mu \mathrm{l}$ of each kidney suspension were added directly to four replicate wells of a ninety-six-well microtitre plate. Plates were sealed and incubated for $3 \mathrm{~h}$ before washing them gently three times to remove non-adherent cells. L-15 $(200 \mu \mathrm{l})$ containing $10 \%$ foetal bovine serum was added to all wells and cultures were incubated at $18^{\circ} \mathrm{C}$ for $2-3 \mathrm{~d}$, after which the respiratory burst activity of the macrophages was determined by incubating the cells with $100 \mu \mathrm{l}$ nitroblue tetrazolium salt $(1 \mathrm{mg} / \mathrm{ml})$-phorbol myristate acetate $(1 \mu \mathrm{g} / \mathrm{ml})$. This was added to three of the four wells and incubated at $18-20^{\circ} \mathrm{C}$ for $40 \mathrm{~min}$. The assay was developed as described by the authors using a microplate reader as described earlier to read the absorbance at $620 \mathrm{~nm}$. The remaining well was used to determine the numbers of macrophages attached to the plate for individual kidney samples ${ }^{30}$. The results were expressed as 'macrophage activity' by calculating the mean optical density for each of the triplicate cultures and dividing the mean optical density by the number of cells per well to obtain an optical density per $10^{5}$ cells and multiplying by 100 .

\section{Histological examination of fish tissues}

Samples were collected at 64 weeks to identify any effects of dietary treatment on the histology of the heart, liver or intestine. Samples of proximal, mid and distal intestine were collected from six fish from each dietary treatment, in addition to the heart and liver, for histopathological examination. Sections were fixed in $10 \%$ buffered formalin at the time of dissection, embedded in paraffin wax and $5 \mu \mathrm{m}$ sections were cut and stained with haematoxylin and eosin. Processed sections were examined 'blind' to eliminate bias in interpretation. Stained sections of heart were assessed for signs of endocarditis and pericarditis. Liver sections were assessed on fat content, any indication of inflammation in the tissue, the degree of peri-vascular cuffing and finally the presence of single cell necrosis. Intestinal sections were examined on the integrity of the intestinal mucosa, the appearance of the submucosa and lamina propria, and the presence of any inflammatory response.

\section{Statistical analysis}

Results are reported as means and standard deviations (n 3) unless otherwise stated. All statistical analyses were performed using the statistical computer package Prism 4.0 (GraphPad Software Inc., San Diego, CA, USA). The significance of treatment effects on biometry and growth rates, liver and leucocyte fatty acid compositions, haematology, serum lysozyme activity and macrophage respiratory burst activity were determined by one-way ANOVA followed by Tukey's multiple comparison test where appropriate. Percentage data and data which were identified as non-homogeneous (Bartlett's test) were subjected to either arcsine, square root or $\log$ transformation before analysis. Differences were reported as significant at $P<0 \cdot 05^{31}$. Immune parameter results are reported as means and standard deviations $(n 8)$.

\section{Results}

There were no significant differences in the total length of fish between dietary treatments, but fish fed Diet B showed significantly lower values for total live mass and liver mass than fish fed Diets A (control) and C. Fish fed Diets A (control) and B presented significantly lower values for flesh dry mass $(\%)$ at the end of the 64-week feeding trial (Table 3).

The total lipid fatty acid compositions of livers from sea bass following 64 weeks of feeding the experimental diets

Table 3. Effect of partial replacement (60\%) of dietary fish oil with vegetable oils (rapeseed, linseed and palm oils) on growth and performance of European sea bass fed experimental diets for 64 weeks* (Mean values and standard deviations)

\begin{tabular}{|c|c|c|c|c|c|c|c|c|}
\hline & \multicolumn{2}{|c|}{ Initial } & \multicolumn{2}{|c|}{ Diet A (control) } & \multicolumn{2}{|c|}{ Diet B } & \multicolumn{2}{|c|}{ Diet C } \\
\hline & Mean & SD & Mean & SD & Mean & SD & Mean & SD \\
\hline Fish length (cm) & 7.9 & 0.5 & 24.9 & $1 \cdot 3$ & $23 \cdot 2$ & 1.4 & $24 \cdot 1$ & 1.4 \\
\hline Fish live mass $(\mathrm{g})$ & $5 \cdot 2$ & $1 \cdot 0$ & $176 \cdot 2^{\mathrm{a}}$ & 32.9 & $143 \cdot 2^{b}$ & $29 \cdot 4$ & $159 \cdot 8^{a b}$ & $34 \cdot 2$ \\
\hline Hepatosomatic index & 1.4 & 0.2 & $2 \cdot 0$ & 0.3 & 1.9 & 0.2 & $2 \cdot 1$ & 0.3 \\
\hline Flesh dry mass (\%) & & & $22 \cdot 9^{b}$ & 1.7 & $21 \cdot 3^{b}$ & 1.5 & $26 \cdot 0^{a}$ & $1 \cdot 4$ \\
\hline Food conversion ratio (feed/gain) & & & $1 \cdot 2$ & 0.3 & 1.6 & 0.4 & 1.3 & 0.3 \\
\hline Fulton's condition factor $(K) \dagger$ & & & $1 \cdot 14$ & $0 \cdot 2$ & $1 \cdot 15$ & 0.3 & $1 \cdot 14$ & $0 \cdot 2$ \\
\hline Specific growth rate & & & 0.8 & 0.1 & 0.7 & 0.1 & 0.8 & 0.1 \\
\hline
\end{tabular}

\footnotetext{
${ }^{a, b}$ Mean values within a row with unlike superscript letters were significantly different $(P<0.05)$.

* See Tables 1 and 2 for details of diets. For fish length and weight, $n 90$; for liver mass, hepatosomatic index and flesh mass, $n 30$ $\dagger K=\left(W / L^{3}\right) \times 100$, where $W$ is the weight $(\mathrm{g})$ and $L$ is the total length $(\mathrm{cm})$.

$\ddagger$ Specific growth rate $=\left(\operatorname{Ln} W_{1}-\operatorname{Ln} W_{0}\right) \times 100 / t$, where $W$ is the weight $(\mathrm{g}), L$ is the length $(\mathrm{cm}), W_{0}$ is the initial weight $(\mathrm{g}), W_{1}$ is the final weight $(\mathrm{g}), t$ is the time $(\mathrm{d})$.
} 
are shown in Table 4. Total SFA (primarily 16:0) were identical in all treatments. Total MUFA, primarily oleic acid (OA), were significantly higher in liver total lipids from fish fed Diet C, followed by fish fed Diets B and A (control) due to the higher inclusion of $\mathrm{OA}$ in the $\mathrm{VO}$ blends. The proportion of linoleic acid $(18: 2 n-6)$ in total lipid from liver was highest in fish fed the VO diets, due to the high inclusion of linoleic acid in RO, LO and PO, and was about $50 \%$ lower in liver of fish fed Diet A (control). However, total $n$-6 PUFA values were not significantly different for all treatments. In contrast, arachidonic acid (ARA; 20:4n-6) was highest in liver of control fish (Diet A) and fish fed Diet B, followed by fish fed Diet C. Total n-6 highly unsaturated fatty acid, primarily ARA, was highest in liver from fish that had been fed Diet A (control) followed by fish from treatments B and $\mathrm{C}$ that showed identical values. The percentage of linolenic acid $(18: 3 n-3)$ in liver total lipids was highest in fish fed Diets $\mathrm{B}$ and $\mathrm{C}$ (which contained the highest proportions of LO and, in consequence, the highest level of linolenic acid), followed by fish fed Diet A (control). Liver total lipid percentages of EPA, DHA and total $n$-3 PUFA were highest in fish fed Diet A (control) due to the highest content of these fatty acids in FO. The level of total PUFA was not significantly different in liver total lipids from all treatments (Table 4).

Table 4. Total lipid content (\% of dry mass) and total lipid fatty acid composition (weight \% of total fatty acids) of liver from European sea bass fed the experimental diets for 64 weeks*

(Mean values and standard deviations for three determinations)

\begin{tabular}{|c|c|c|c|c|c|c|}
\hline & \multicolumn{2}{|c|}{$\begin{array}{c}\text { Diet A } \\
\text { (control) }\end{array}$} & \multicolumn{2}{|c|}{ Diet B } & \multicolumn{2}{|c|}{ Diet C } \\
\hline & Mean & SD & Mean & SD & Mean & SD \\
\hline Total lipid (\%) & 54.8 & $7 \cdot 6$ & $52 \cdot 9$ & 0.9 & $54 \cdot 7$ & $5 \cdot 8$ \\
\hline \multicolumn{7}{|l|}{ Fatty acid (\%) } \\
\hline $14: 0$ & $1 \cdot 8^{\mathrm{a}}$ & 0.3 & $1 \cdot 3^{\mathrm{ab}}$ & 0.2 & $1.0^{\mathrm{b}}$ & 0.1 \\
\hline $15: 0$ & $0.2^{\mathrm{a}}$ & $0.0 \dagger$ & $0.2^{\mathrm{a}}$ & 0.0 & $0.1^{b}$ & 0.0 \\
\hline $16: 0$ & $16 \cdot 6$ & $2 \cdot 4$ & $16 \cdot 1$ & $2 \cdot 1$ & $17 \cdot 3$ & $2 \cdot 1$ \\
\hline $18: 0$ & $3 \cdot 1$ & 0.7 & $3 \cdot 7$ & 0.2 & 3.4 & 0.7 \\
\hline Total SFA & 22.4 & $3 \cdot 1$ & 21.8 & 2.5 & $22 \cdot 5$ & $2 \cdot 9$ \\
\hline $16: 1 n-9 / n-7$ & $8 \cdot 8^{\mathrm{a}}$ & 1.0 & $6 \cdot 0^{\mathrm{b}}$ & 1.0 & $6 \cdot 1^{\mathrm{b}}$ & 0.2 \\
\hline $18: 1 n-9$ & $28 \cdot 8^{\mathrm{b}}$ & $2 \cdot 0$ & $34 \cdot 1^{\mathrm{ab}}$ & $2 \cdot 2$ & $39 \cdot 2^{\mathrm{a}}$ & $2 \cdot 3$ \\
\hline $18: 1 n-7$ & $3 \cdot 4^{\mathrm{a}}$ & 0.4 & $2 \cdot 5^{\mathrm{b}}$ & 0.2 & $2 \cdot 7^{\mathrm{ab}}$ & 0.2 \\
\hline $20: 1 n-9$ & $2 \cdot 1$ & $0 \cdot 1$ & $2 \cdot 0$ & 0.2 & $2 \cdot 1$ & 0.3 \\
\hline $22: 1 n-11$ & 0.7 & 0.0 & 0.6 & 0.0 & 0.5 & 0.1 \\
\hline Total MUFA & $44 \cdot 7^{\mathrm{b}}$ & 1.2 & $46 \cdot 1^{\mathrm{b}}$ & 1.5 & $51 \cdot 3^{\mathrm{a}}$ & 1.6 \\
\hline $18: 2 n-6$ & $3 \cdot 3^{b}$ & 0.3 & $6 \cdot 4^{\mathrm{a}}$ & 1.5 & $6 \cdot 2^{\mathrm{a}}$ & 1.3 \\
\hline $20: 4 n-6$ & $0.5^{\mathrm{a}}$ & $0 \cdot 1$ & $0.3^{\mathrm{ab}}$ & 0.1 & $0.2^{b}$ & 0.0 \\
\hline Total $n-6$ & 4.9 & 0.5 & $7 \cdot 6$ & 1.4 & $7 \cdot 2$ & 1.5 \\
\hline $18: 3 n-3$ & $0.8^{b}$ & 0.2 & $7 \cdot 5^{\mathrm{a}}$ & $2 \cdot 8$ & $5 \cdot 1^{\mathrm{a}}$ & 1.2 \\
\hline $18: 4 n-3$ & $1 \cdot 0^{\mathrm{a}}$ & 0.1 & $0.9^{\mathrm{ab}}$ & 0.1 & $0.7^{b}$ & $0 \cdot 1$ \\
\hline $20: 4 n-3$ & 0.5 & $0.0 a$ & $0.3^{\mathrm{ab}}$ & 0.1 & $0.2^{b}$ & 0.0 \\
\hline $20: 5 n-3$ & $6 \cdot 2$ & $0.7 a$ & $3 \cdot 2^{b}$ & 1.0 & $2 \cdot 5^{b}$ & 0.6 \\
\hline $22: 5 n-3$ & $1 \cdot 2$ & $0.1 \mathrm{a}$ & $0.6^{b}$ & 0.2 & $0.4^{\mathrm{b}}$ & 0.1 \\
\hline $22: 6 n-3$ & $10 \cdot 2$ & $1.6 a$ & $5 \cdot 4^{\mathrm{b}}$ & 1.8 & $4 \cdot 2^{\mathrm{b}}$ & 0.9 \\
\hline Total $n-3$ & $21 \cdot 1$ & $2.5 a$ & $19 \cdot 3^{\mathrm{ab}}$ & 0.5 & $13 \cdot 8^{\mathrm{b}}$ & $2 \cdot 9$ \\
\hline Total PUFA & $26 \cdot 0$ & 2.9 & $27 \cdot 0$ & $1 \cdot 1$ & $21 \cdot 1$ & 4.4 \\
\hline$n-3 / n-6$ & 4.3 & $0.8^{a}$ & $2 \cdot 5^{\mathrm{b}}$ & 0.7 & $1.9^{\mathrm{b}}$ & 0.9 \\
\hline
\end{tabular}

a,b Mean values within a row with unlike superscript letters were significantly different $(P<0.05)$.

* See Tables 1 and 2 for details of diets.

†Standard deviation of 0.0 implies SD $<0.05$.
Inclusion of VO in the diets of sea bass modified the fatty acid composition of their PBL. The fatty acid compositions of PBL from VO-fed fish were different from the corresponding PBL of fish fed FO, with the latter having more MUFA and higher $n-6$ PUFA. PBL of sea bass maintained on Diets $\mathrm{B}$ and $\mathrm{C}$ had significantly increased levels of 18: 0, OA, linoleic acid, 20:2n-6 and linolenic acid, and significantly reduced amounts of $n$-3 PUFA, ARA, EPA, DHA and others (Table 5). The overall ratio of $n-3 / n-6$ was significantly reduced in sea bass fed the VO diets.

The effect of partial replacement of dietary FO with VO blends on the concentration of plasma $\mathrm{PGE}_{2}$ in European sea bass after 64 weeks of feeding the diets is shown in Fig. 1(a). The highest values were found in plasma of fish fed the control (FO) diet and Diet $\mathrm{C}$, with significantly lower values seen in fish fed Diet B (46\% less). The source of dietary lipid did not affect any of the haematological parameters measured. No significant differences were found in haematocrit values (Fig. 1(b)) or the total number of leucocytes (Fig. 1(c)) and erythrocytes (Fig. 1(d)) between groups. The production of superoxide anion by head kidney macrophages, measured by the reduction of nitroblue tetrazolium salt, is presented in Fig. 1(e). It appears that following phorbol myristate acetate triggering, the respiratory burst activity was significantly reduced in fish fed the VO-based diets. Whether or not this change affects the innate immune

Table 5. Total lipid fatty acid composition (weight $\%$ of total fatty acids) of peripheral blood leucocytes from European sea bass fed the experimental diets for 64 weeks ${ }^{*}$

(Mean values and standard deviations for three determinations)

\begin{tabular}{|c|c|c|c|c|c|c|}
\hline \multirow[b]{2}{*}{ Fatty acid } & \multicolumn{2}{|c|}{$\begin{array}{c}\text { Diet A } \\
\text { (control) }\end{array}$} & \multicolumn{2}{|c|}{ Diet B } & \multicolumn{2}{|c|}{ Diet C } \\
\hline & Mean & SD & Mean & SD & Mean & SD \\
\hline $14: 0$ & $1.6^{\mathrm{a}}$ & $0.0 \dagger$ & $1.0^{\mathrm{b}}$ & 0.2 & $1 \cdot 1^{\mathrm{b}}$ & 0.1 \\
\hline $15: 0$ & $0.5^{\mathrm{a}}$ & 0.1 & $0.3^{\mathrm{b}}$ & 0.0 & $0.3^{\mathrm{b}}$ & 0.1 \\
\hline $16: 0$ & $17 \cdot 2$ & 1.4 & $16 \cdot 8$ & 0.6 & $16 \cdot 7$ & 0.8 \\
\hline $18: 0$ & $3 \cdot 9^{\mathrm{a}}$ & 0.2 & $5 \cdot 6^{\mathrm{b}}$ & 0.5 & $4 \cdot 7^{\mathrm{C}}$ & 0.3 \\
\hline Total SFA & 23.5 & 1.8 & $24 \cdot 0$ & 0.7 & 23.1 & 0.7 \\
\hline $16: 1 n-9 / n-7$ & $3 \cdot 4^{\mathrm{a}}$ & 0.4 & $2 \cdot 5^{\mathrm{b}}$ & 0.5 & $2 \cdot 6^{\mathrm{b}}$ & 0.2 \\
\hline $18: 1 n-9$ & $10 \cdot 5^{\mathrm{a}}$ & 1.7 & $18 \cdot 8^{\mathrm{b}}$ & 0.4 & $20.4^{\mathrm{b}}$ & 1.8 \\
\hline $18: 1 n-7$ & $2 \cdot 0$ & 0.2 & 1.9 & 0.2 & 1.9 & 0.1 \\
\hline $20: 1 n-9$ & 1.7 & 0.2 & 1.8 & 0.2 & 1.8 & 0.3 \\
\hline $22: 1 n-11$ & 0.9 & 0.2 & 1.0 & 0.3 & 1.0 & 0.3 \\
\hline Total MUFA & $20 \cdot 1^{a}$ & $2 \cdot 7$ & $27 \cdot 6^{\mathrm{b}}$ & 1.4 & $28.9^{\mathrm{b}}$ & 2.6 \\
\hline $18: 2 n-6$ & $2 \cdot 6^{a}$ & 0.2 & $5 \cdot 8^{\mathrm{b}}$ & 0.4 & $6 \cdot 1^{b}$ & 0.7 \\
\hline $20: 4 n-6$ & $1 \cdot 2^{\mathrm{a}}$ & 0.1 & $0.7^{\mathrm{b}}$ & 0.1 & $0.7^{\mathrm{b}}$ & 0.1 \\
\hline Total $n-6$ & $4.9^{\mathrm{a}}$ & 0.4 & $7 \cdot 5^{\mathrm{b}}$ & 0.5 & $7 \cdot 7^{\mathrm{b}}$ & 0.7 \\
\hline $18: 3 n-3$ & $0.7^{\mathrm{a}}$ & 0.2 & $5 \cdot 9^{b}$ & 0.5 & $4 \cdot 8^{\mathrm{C}}$ & 0.6 \\
\hline $18: 4 n-3$ & $0.9^{\mathrm{a}}$ & 0.2 & $0.7^{\mathrm{ab}}$ & 0.1 & $0.6^{\mathrm{b}}$ & 0.1 \\
\hline $20: 4 n-3$ & $0.3^{\mathrm{a}}$ & 0.1 & $0 \cdot 2^{b}$ & 0.2 & $0.2^{b}$ & 0.0 \\
\hline $20: 5 n-3$ & $13 \cdot 4^{\mathrm{a}}$ & 0.5 & $8.9^{b}$ & 0.2 & $8 \cdot 3^{\mathrm{b}}$ & 0.4 \\
\hline $22: 5 n-3$ & $1 \cdot 2^{\mathrm{a}}$ & 0.1 & $0.9^{b}$ & 0.2 & $0.8^{\mathrm{b}}$ & 0.0 \\
\hline $22: 6 n-3$ & $27 \cdot 6^{a}$ & $2 \cdot 6$ & $19 \cdot 7^{b}$ & 1.0 & $20 \cdot 6^{\mathrm{b}}$ & 2.9 \\
\hline Total $n-3$ & $44 \cdot 1^{a}$ & 2.6 & $36 \cdot 4^{b}$ & 1.5 & $35 \cdot 3^{b}$ & 2.6 \\
\hline Total PUFA & $49 \cdot 1^{a}$ & $2 \cdot 4$ & $43.9^{\mathrm{b}}$ & 1.9 & $43 \cdot 1^{b}$ & $2 \cdot 2$ \\
\hline$n-3 / n-6$ & $9.0^{\mathrm{a}}$ & $1 \cdot 2$ & $4 \cdot 8^{\mathrm{b}}$ & 0.2 & $4 \cdot 6^{\mathrm{b}}$ & 0.7 \\
\hline
\end{tabular}

a,b,c Mean values within a row with unlike superscript letters were significantly different $(P<0.05)$.

* See Tables 1 and 2 for details of diets.

† Standard deviation of 0.0 implies SD $<0.05$. 

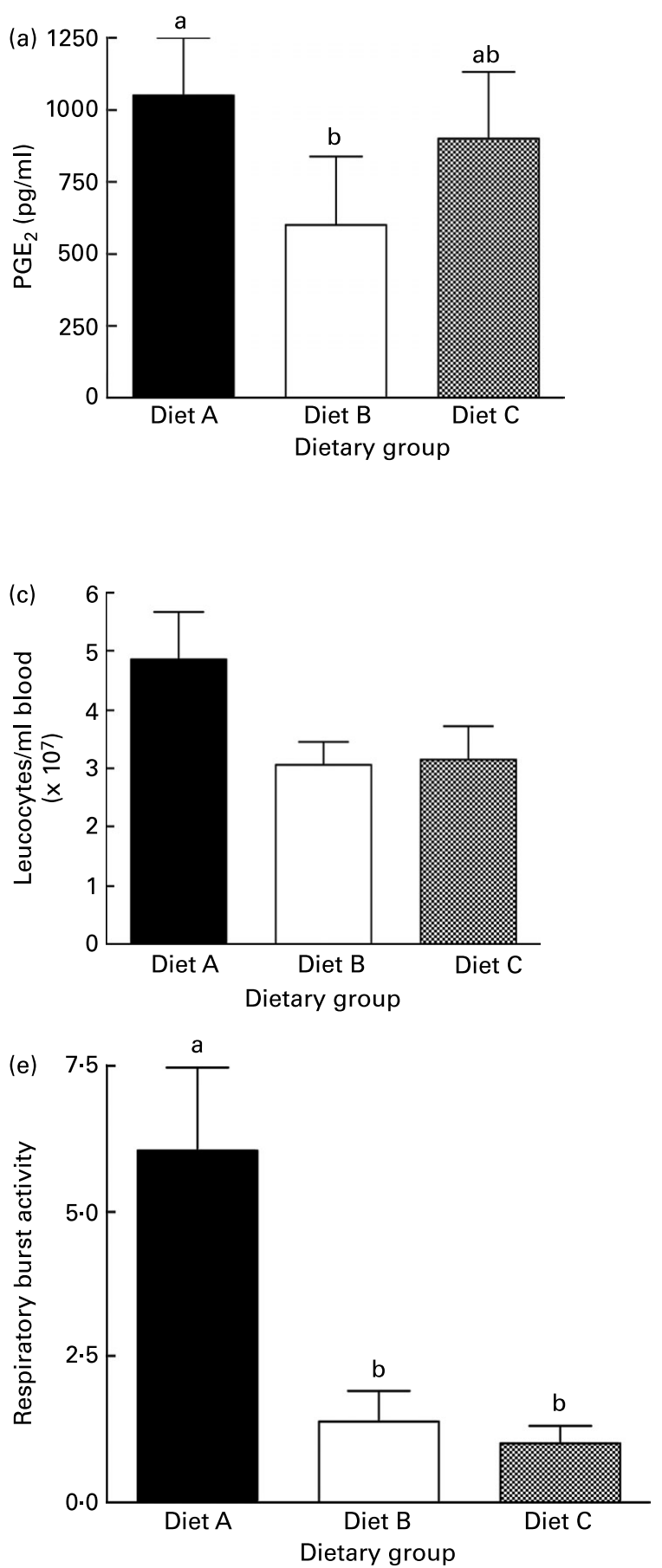
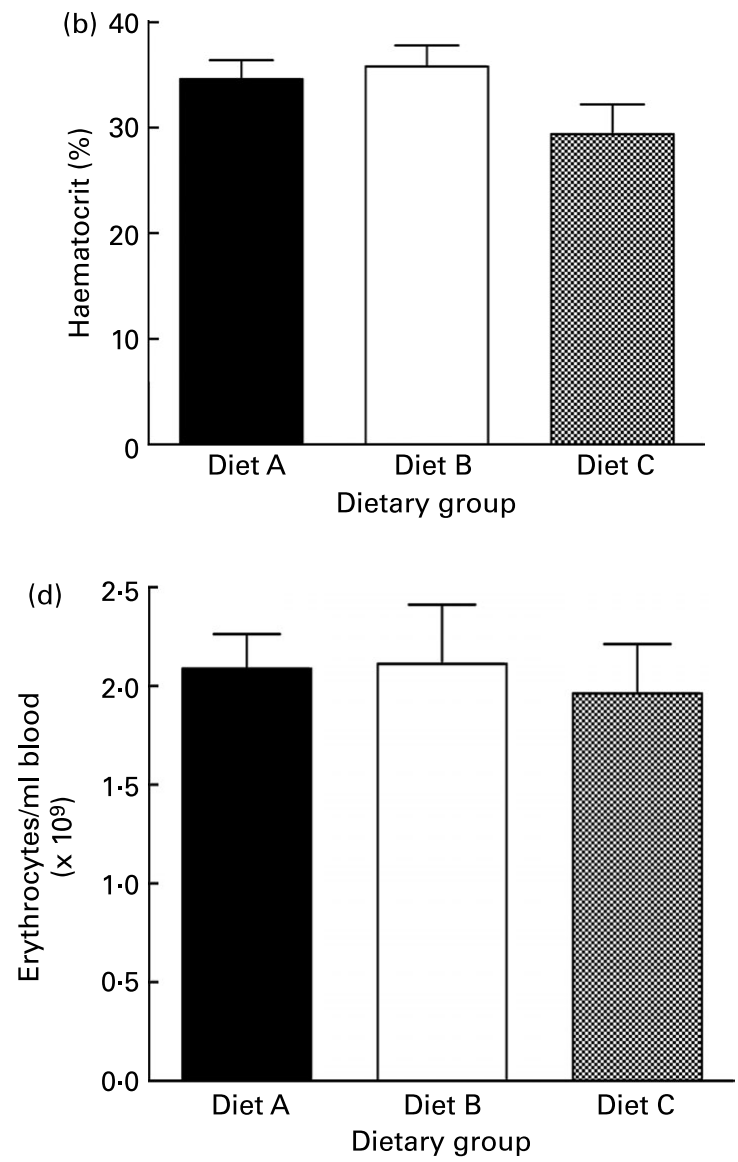

(f)

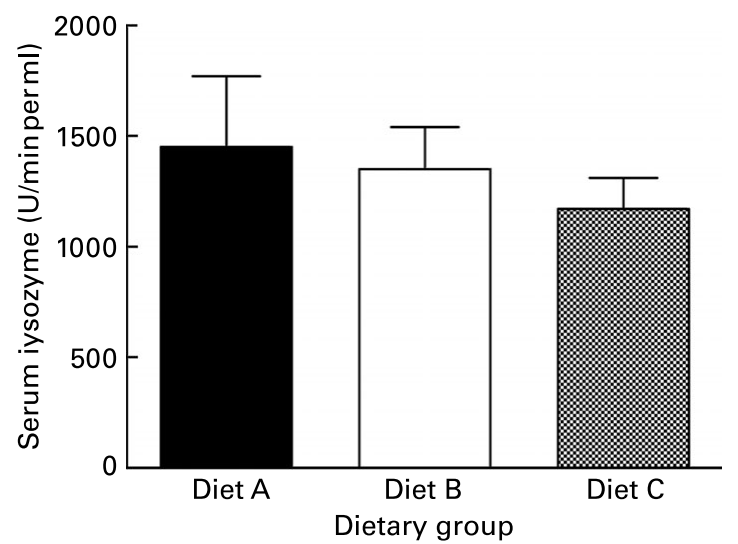

Fig. 1. Effects of feeding diets containing fish oil (Diet A), or two $60 \%$ vegetable oil blends (Diets $B$ and $C$ ) on plasma prostaglandin $E_{2}$ (PGE $E_{2}$ ) concentration (a); $\%$ haematocrit (b); total circulating leucocytes (c); total circulating erythrocytes (d); head kidney macrophage activity (nitroblue tetrazolium salt reduction, measured as absorbance at $620 \mathrm{~nm} / 10^{5}$ cells $\left.\times 100\right)(e)$; serum lysozyme activity (f). Values are means with their standard errors depicted by vertical bars $(n$ ). a,b Mean values with unlike letters were significantly different $(P<0.05)$.

response of the fish needs further investigation. It could be that the respiratory burst event takes place earlier or later than seen with macrophages from fish fed the FO diet and that this activity has not been measured at the optimal time for fish fed the VO diets. No effect of dietary VO was observed on sea bass serum lysozyme activity (Fig. 1(f)). Fish fed the FO diet showed the highest $(1452.5 \mathrm{U} / \mathrm{ml}$ per min; but not significantly different) value of lysozyme activity in serum compared to $1351 \cdot 1 \mathrm{U} / \mathrm{ml}$ per min found for fish fed Diet B and $1171 \cdot 1 \mathrm{U} / \mathrm{ml}$ per min for Diet $\mathrm{C}$.

Hearts examined from all three dietary groups showed no signs of pathological change. In livers, fat vacuoles were variable in size in many sections with some very large vacuoles present within some hepatocytes and relatively smaller vacuoles in other hepatocytes. Due to the level of vacuolation in some hepatocytes, there was some distortion 
of the cellular architecture and occasional breakdown of cells. Again, there were no differences between the three dietary groups. Small foci of inflammation were seen in some sections in all three groups, with a slightly higher incidence in sections from the Diet $\mathrm{C}$ group. Peri-vascular cuffing was not a feature in any of the dietary groups examined. With regard to the intestinal sections, mucus levels appeared very similar in all segments and in all dietary groups. Absorptive vacuoles were small and multiple in all sections. In the FO diet these were at relatively low levels in the proximal and mid-segments and higher in the distal segments. In fish fed Diet B or Diet $\mathrm{C}$, vacuolation in the proximal segments appeared to be much more pronounced, interestingly less so than in the mid-sections. Some cellular infiltration was seen in the lamina propria of one fish in the FO diet group (Fig. 2(a)) and two fish on Diet C (Fig. 2(b)). Sloughing of the mucosal membrane was not a feature in any of the sections examined. The major difference seen between these groups was the level of absorptive vacuolation in the proximal segment of fish fed Diet B or Diet C, compared with the FO diet.

\section{Discussion}

Considerable data have been accumulated on the effects of different dietary lipids on tissue fatty acid compositions of both mammals and fish, although the effects of dietary lipids on fish health and immune function are less well documented.

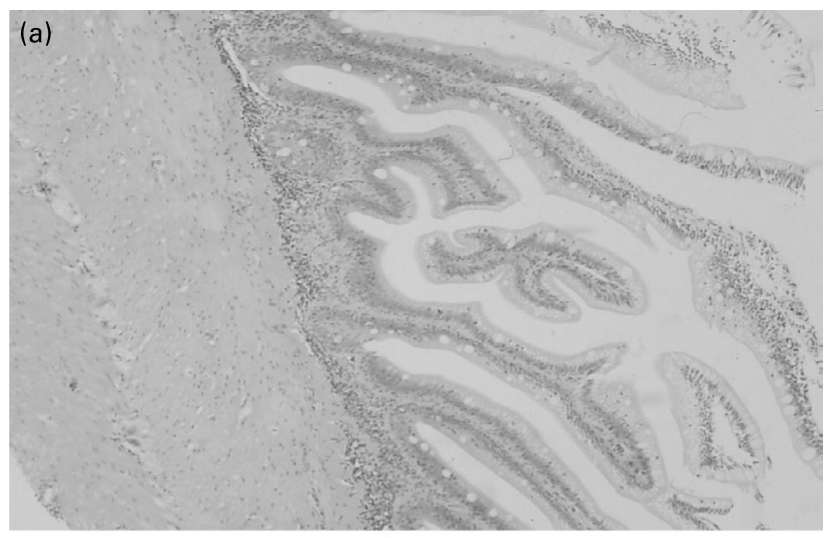

(b)

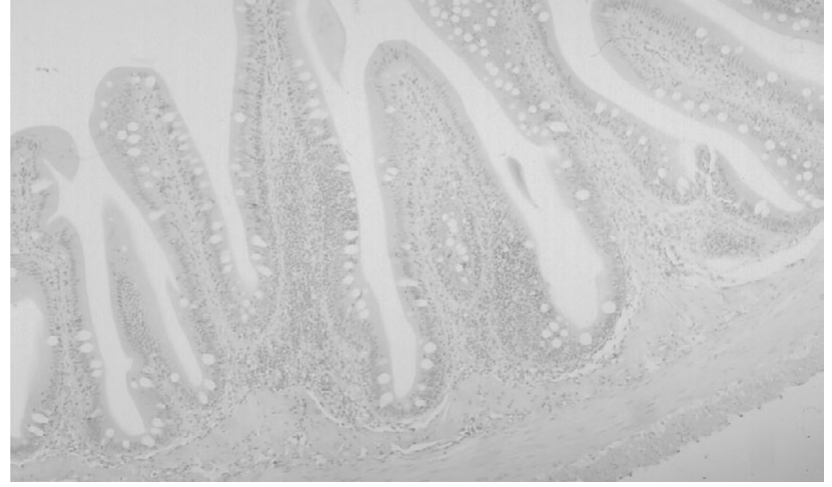

Fig. 2. Histopathology of sea bass fed fish oil (Diet A), distal intestine showing slight cellular infiltration in the lamina propria and high levels of absorptive vacuoles $(\times 175)(a) ; 60 \%$ vegetable oil blend (Diet $C)$, distal intestine showing cellular infiltration but no sloughing of the mucosal folds $(\times 430)(b)$.
Changes in dietary fatty acid composition have been shown to affect both innate ${ }^{32-35}$ and adaptive immunity ${ }^{16,34,36-38}$, as well as the resistance to infectious diseases ${ }^{16,36-39}$. However, the role of $n-3$ and $n-6$ fatty acids in fish immune response is unclear, and reports are not conclusive and are often contradictory.

The modulatory process is likely to occur at different cellular levels with the most obvious being a change in cell membrane phospholipid fatty acid composition, affecting the activity of membrane-bound enzymes, receptors and ion channels ${ }^{40}$. In addition, eicosanoids, a group of bioactive derivatives of ARA, EPA and dihomo- $\gamma$-linolenic acid (20:3n-6), which include PG, thromboxanes, leukotrienes and lipoxins, act to regulate the immune response $\mathrm{e}^{13,41}$. Other immune modulatory processes involving fatty acids include changes in intracellular signalling pathways ${ }^{42}$ and direct interactions between fatty acids and nuclear transcription factors in cells of the immune system, such as PPAR, that act to regulate immune cell function ${ }^{20}$.

Fish tissues and cell membranes, including phagocytic cells (macrophages, neutrophils), contain relatively high concentrations of $n-3$ PUFA, and their compositions can be altered by changes in dietary lipid ${ }^{18}$. Specific macrophage functions may also be altered by lipids, mainly due to changes in membrane fluidity. If fluidity is altered by fatty acid composition, then potentially several aspects of phagocyte function may be affected including phagocytosis and eicosanoid production. Calder et $a l .{ }^{43}$ reported that unsaturated fatty acid incorporation is associated with an increase in the phagocytosis of zymosan particles.

Reduction in head kidney macrophage respiratory burst activity has been observed in sea bass and gilthead sea bream fed $\mathrm{VO}^{9,44}$. Sea bass fed $60 \% \mathrm{RO}, \mathrm{LO}$ and olive oil had significantly reduced phagocytic capacity of head kidney macrophage to engulf yeast particles ${ }^{9}$ while Montero et al. ${ }^{44}$ found reduced macrophage activity in sea bream fed $60 \%$ RO. In addition, Sheldon \& Blazer ${ }^{32}$ found that channel catfish macrophage killing activity was positively correlated to the dietary content of $n-3$ PUFA. They found phagocytosis of live Edwardsiella ictaluri by catfish head kidney macrophages was not significantly affected by feeding soyabean oil compared to fish fed menhaden oil or beef tallow. However, feeding soyabean oil significantly reduced the ability of macrophages to kill engulfed bacteria compared to macrophages from those fed menhaden oil. Macrophages from the latter group also had a significantly higher killing index than macrophages from fish fed soyabean oil. Waagbø et $a{ }^{34}{ }^{34}$ showed that Atlantic salmon fed diets rich in $n-3$ PUFA significantly reduced the bacterial killing ability of macrophages at $12^{\circ} \mathrm{C}$ but not at $18^{\circ} \mathrm{C}$, indicating that temperature, perhaps related to membrane fluidity, also influences the activity of macrophages. In contrast, Thompson et al. ${ }^{16}$ found no differences in phagocytosis and bactericidal activities of head kidney macrophages from Atlantic salmon fed diets enriched with either $n-3$ or $n-6$ PUFA.

In the present study, the concentration of circulating $\mathrm{PGE}_{2}$ in plasma of sea bass fed the $60 \%$ VO blend (Diet B) was significantly lower than in fish fed FO. In addition, the fish fed $60 \%$ VO (Diets B and C) also showed significantly reduced respiratory burst activity which coincided with a reduction in plasma $\mathrm{PGE}_{2}$ levels. Since the production of $\mathrm{PGE}_{2}$ was 
reduced in fish fed VO diets, it may be that the activity or expression of the cyclo-oxygenase enzymes is inhibited by dietary lipid. It is also possible that feeding VO for a long period may reduce the levels of ARA in plasma membranes and, thereby, compromise immune function. In support of the present study, a number of studies also showed a reduction in production of $\mathrm{PGE}_{2}$ and leukotriene $\mathrm{B}_{4}$ by stimulated head kidney macrophages from salmon fed a diet containing LO compared to those fed diets containing sunflower oil or $\mathrm{FO}^{17,18,45,46}$. However, no differences in serum lysozyme activity were found in the present study, which was also reported in other studies with fish fed $\mathrm{VO}^{18,44}$.

Montero et $a l^{44}$ found that seabream fed a FO diet had higher numbers of circulating erythrocytes compared to fish fed $60 \%$ LO or soyabean oil diets, which may be related to a higher oxygen requirement due to higher peroxisomal $\beta$ oxidation activity induced by the VO diets ${ }^{37}$. Leray et al. ${ }^{47}$ found that the fatty acid composition of erythrocyte membrane phospholipids from trout can be profoundly altered by dietary oils. Trout fed highly saturated coconut oil showed increased $n-9$ fatty acids in their phospholipids, and, consequently, their erythrocytes had a more shrunken appearance than fish fed FO. Perhaps the high levels of saturates in the diets caused reduced haematocrit levels, linked to a shrunken erythrocyte morphology causing a lower packed erythrocyte volume.

The lipid composition of monocytes, macrophages, lymphocytes and polymorphonuclear cells reflect the fatty acid composition of dietary lipids in mammals ${ }^{11,48}$. Studies by Waagbb $\varnothing$ et $a .^{35}$, Farndale et $a .^{49}$ and Montero et al. ${ }^{44}$ reported that dietary oil determines the fatty acid profile of macrophages and immune cells in cod, sea bass and sea bream. Montero et $a l^{44}$ reported selective incorporation of certain fatty acids into head kidney macrophages of sea bream. DHA was found to be preferentially incorporated and retained in this cell type. Generally, fish fed with a VO-containing diet had increased levels of oleic acid, linoleic acid, linolenic acid and total $n-6$ PUFA in both their liver and their PBL, and decreased levels of EPA, DHA, total n-3 PUFA and a lower $n-3 / n-6$ ratio than fish fed a FO diet. Fish fed a FO diet showed the highest $n$-3 highly unsaturated fatty acids in immune cells in the present study and in previous studies ${ }^{35,44,49}$. Evidence suggests that changing the fatty acid composition of immune cells can influence immune function by changing the physiology of the cell membrane but perhaps more importantly by influencing the production of modulatory PG and leukotrienes ${ }^{20}$. The production of eicosanoids is influenced, in part, by the availability of precursor fatty acids and, in particular, the EPA/ARA ratio. In a previous study with Atlantic salmon fed a single VO, 3-fold differences in the EPA/ARA ratio of immune cells were recorded ${ }^{18}$, while in the present study with VO blends the difference in the EPA/ARA ratio, between the three dietary treatments, was only $13 \%$. Perhaps the minor changes to the EPA/ARA ratio in the present study can partly explain the lack of effect observed in innate immune function.

The overall histological appearance of sea bass sampled from all of the dietary treatments was normal with very few differences observed between the groups. The only difference was in the levels of absorptive vacuoles present in the proximal intestine. Sea bass fed the VO diets showed elevated numbers of absorptive vacuoles compared to fish fed the FO diet. The presence of increased absorptive vacuoles tends to suggest an 'active' mucosa, however, with increased mucosal vacuolation this could, in turn, leave the intestinal mucosal membrane more vulnerable to sloughing and breakdown. However, the vacuolisation was minor and was still regarded as being within normal ranges for Atlantic salmon.

Results of the present study suggest that potential exists for replacing FO with a blend of VO in the feeds of farmed sea bass without compromising growth, non-specific immune function and overall histological appearance. It is important to establish that alternative dietary lipids to FO are not only supplied in the correct quantities and balance for optimal growth and feed conversion, but can maintain optimal immune function and not increase susceptibility to infectious pathogens. The present study suggests that normal immune function can be more successfully attained if dietary FO is replaced by a blend of VO that provides a more physiologically balanced fatty acid composition, in comparison to replacement with a single $\mathrm{VO}^{9,17,18,44}$.

\section{Acknowledgements}

This work was supported by contract no. QLRT-2000-30058 of the project 'Researching alternatives to fish oils in aquaculture, RAFOA' of the European Commission, Directorate General Fisheries as part of the Fifth Framework Programme 'Quality of Life \& Management of Living Resources'. Joanne Good was supported in her doctoral studies by Ewos Innovation AS, Norway.

\section{References}

1. Pike IH \& Barlow SM (2002) Impact of fish farming on fish stocks. Aquaculture and Environment Symposium, 7th Bordeaux Aquaculture, Bordeaux Exhibition Centre, France. Book of Abstracts, pp. 6-7.

2. Tacon AGJ (2004) Use of fish meal and fish oil in aquaculture: a global perspective. Aquat Res Cult Dev 1, 3-14.

3. Kaushik SJ, Coves D, Dutto G \& Blanc D (2004) Almost total replacement of fish meal by plant protein sources in the diet of a marine teleost, the European sea bass, Dicentrarchus labrax. Aquaculture 230, 391-404.

4. Tacon AGJ (2005) Salmon aquaculture dialogue: status of information on salmon aquaculture feed and the environment. Int Aquafeed 8, 22-37.

5. Bell JG, Henderson RJ, Tocher DR \& Sargent JR (2004) Replacement of dietary fish oil with increasing levels of linseed oil: modification of flesh fatty acid compositions in Atlantic Salmon (Salmo salar) using a fish oil finishing diet. Lipids 39, 223-232.

6. Torstensen BE, Bell JG, Sargent JR, Rosenlund G, Henderson RJ, Graff IE, Lie $\varnothing \&$ Tocher DR (2005) Tailoring of Atlantic salmon (Salmo salar L.) flesh lipid composition and sensory quality by replacing fish oil with a vegetable oil blend. J Agric Food Chem 53, 10166-10178.

7. Caballero MJ, Obach A, Rosenlund G, Montero D, Gisvold M \& Izquierdo MS (2002) Impact of different dietary lipid sources on growth, lipid digestibility, tissue fatty acid composition and histology of rainbow trout, Oncorhynchus mykiss. Aquaculture 214, 253-271.

8. Izquierdo MS, Obach A, Arantzamendi L, Montero D, Robaina L \& Rosenlund G (2003) Dietary lipid sources for seabream and 
sea bass: growth performance, tissue composition and flesh quality. Aquacult Nutr 9, 397-407.

9. Mourente G, Good JE \& Bell JG (2005) Partial substitution of fish oil with rapeseed, linseed and olive oils in diets for European sea bass (Dicentrarchus labrax L.): effects on flesh fatty acid composition, plasma prostaglandins $E_{2}$ and $F_{2 \alpha}$, immune function and effectiveness of a fish oil finishing diet. Aquacult Nutr 11, 25-40.

10. Blazer VS (1992) Nutrition and disease resistance in fish. Аnnи Rev Fish Dis 2, 309-323.

11. Meade CJ \& Mertin J (1978) Fatty acids and immunity. Adv Lipid Res 16, 127-165.

12. Calder PC (2001) Polyunsaturated fatty acids, inflammation and immunity. Lipids 36, 1007-1024.

13. Yaqoob P (2004) Fatty acids and the immune system: from basic science to clinical applications. Proc Nutr Soc 63, 89-104.

14. Clamp AG, Ladha S, Clark DC, Grimble RF \& Lund EK (1997) The influence of dietary lipids on the composition and membrane fluidity of rat hepatocyte plasma membrane. Lipids 32, 179-184.

15. Sargent JR, Tocher DR \& Bell JG (2002) The lipids. In Fish Nutrition, 3rd ed., pp. 181-257 [JE Halver and RW Hardy, editors]. San Diego, CA: Academic Press.

16. Thompson KD, Henderson RJ \& Tatner MF (1995) A comparison of the lipid composition of peripheral blood cells and head kidney leucocytes of Atlantic salmon (Salmo salar L.). Comp Biochem Physiol B Biochem Mol Biol 112, 83-92.

17. Bell JG, Dick JR, McVicar AH, Sargent JR \& Thompson KD (1993) Dietary sunflower, linseed and fish oils affect phospholipid fatty acid composition, development of cardiac lesions, phospholipase activity and eicosanoid production in Atlantic salmon (Salmo salar). Prostaglandins Leukot Essent Fatty Acids 49, 665-673.

18. Bell JG, Ashton I, Secombes CJ, Weitzel BR, Dick JR \& Sargent JR (1996) Dietary lipid affects phospholipid fatty acid compositions, eicosanoid production and immune function in Atlantic Salmon (Salmo salar). Prostagandins Leukot Essent Fatty Acids 54, 173-182.

19. De Pablo MA \& De Cienfuegos GA (2000) Modulatory effects of dietary lipids on immune system functions. Immunol Cell Biol 78, 31-39.

20. Calder PC (2006) $n$-3 polyunsaturated fatty acids, inflammation, and inflammatory diseases. Am J Clin Nutr 83, 1505S-15019S.

21. Wootten RJ (1990) Ecology of Teleost Fishes. Fish and Fisheries Series 1. Ashburton: Chapman and Hall.

22. Woyewoda AD, Shaw SJ, Ke PJ \& Burns BG (1986) Recommended Laboratory Methods for Assessment of Fish Quality. Canadian Technical Report of Fisheries and Aquatic Sciences no. 1448. Ottawa, Canada: NRC Research Press.

23. Folch J, Lees LM \& Sloane-Stanley GH (1957) A simple method for isolation and purification of total lipids from animal tissues. J Biol Chem 226, 497-509.

24. Christie WW (1982) Lipid Analyses, 2nd ed. Oxford: Pergamon Press.

25. Mourente G \& Tocher DR (1994) In vivo metabolism of $\left[1-{ }^{14} \mathrm{C}\right]$ linolenic acid $[18: 3(n-3)]$ and $\left[1-{ }^{14} \mathrm{C}\right]$ eicosapentaenoic acid $[20: 5(n-3)]$ in a marine fish: time course of the desaturation/elongation pathway. Biochim Biophys Acta 1212, $109-118$.

26. Bell JG, Tocher DR, Macdonald FM \& Sargent JR (1994) Effects of diets rich in linoleic $(18: 2 n-6)$ and $\alpha$-linolenic $(18: 3 n-3)$ acids on the growth, lipid class and fatty acid compositions and eicosanoid production in juvenile turbot (Scophthalmus maximus L). Fish Physiol Biochem 13, $105-118$.
27. Anderson DP \& Siwicki AK (1994) Simplified assays for measuring non-specific defense mechanisms in fish. Am Fish Soc (Fish Health Sect) 12, 26-35.

28. Rungruangsak-Torrissen K, Wergeland HI, Glette J \& Waagbø R (1999) Disease resistance and immune parameters in Atlantic salmon (Salmo salar L.) with genetically different trypsin isozymes. Fish Shellfish Immunol 9, 557-568.

29. Chung S \& Secombes CJ (1988) Analysis of events occurring within teleost macrophages during the respiratory burst. Comp Biochem Physiol B Biochem Mol Biol 89, 539-544.

30. Secombes CJ (1990) Isolation of salmonid macrophages and analysis of their killing activity. In Techniques in Fish Immunology, pp. 137-154 [JS Stolen, TC Fletcher, DP Anderson, BS Robertson and WB van Muiswinkel, editors]. Trenton, New Jersey: SOS Publications.

31. Zar JH (1984) Biostatistical Analysis, 2nd ed. Englewood Cliffs, NJ: Prentice-Hall.

32. Sheldon WM \& Blazer VS (1991) Influence of dietary lipid and temperature on bactericidal activity of channel catfish macrophages. J Aquat Anim Health 3, 87-93.

33. Obach A, Quentel C \& Laurencin FB (1993) Effects of $\alpha$-tocopherol and dietary oxidized fish oil on the immune response of sea bass Dicentrarchus labrax. Dis Aquat Org 15, 175-185.

34. Waagbø R, Sandnes K, Joergensen J, Engstad R, Glette J \& Lie $\varnothing(1993)$ Health aspects of dietary lipid sources and vitamin E in Atlantic salmon (Salmo salar): 2 - spleen and erythrocyte phospholipid fatty acid composition, nonspecific immunity and disease resistance. Fiskeridir Skr (Ernaering) 6, 63-80.

35. Waagbø R, Hemre GI, Holm JC \& Lie Ø (1995) Tissue fatty acid composition, haematology and immunity in adult cod, Gadus morhua L., fed three dietary lipid sources. J Fish Dis 18, 615-622.

36. Erdal JI, Evensen O, Kaurstad OK, Lillehaug A, Solbakken R \& Thorud K (1991) Relationship between diet and immune response in Atlantic salmon (Salmo salar $\mathrm{L}$ ) after feeding various levels of ascorbic acid and omega-3 fatty acids. Aquaculture 98, 363-379.

37. Waagbø R, Sandnes K, Lie $\varnothing$ \& Nilsen ER (1993) Health aspects of dietary lipid sources and vitamin $\mathrm{E}$ in Atlantic Salmon (Salmo salar): 1 - erythrocyte total lipid fatty acid composition, haematology and humoral immune response. Fiskeridir Skr (Ernaering) 6, 47-62.

38. Fracolossi DM \& Lovell RT (1994) Dietary lipid sources influence responses of channel catfish (Ictalarus punctatus) to challenge with the pathogen Edwardsiella ictaluri. Aquaculture 119, 287-298.

39. Salte R, Thomassen MS \& Wold K (1988) Do high levels of dietary polyunsaturated fatty acids (EPA/DHA) prevent disease associated with membrane degeneration in farmed Atlantic salmon at low water temperatures? Bull Eur Assoc Fish Path 8, 63-65.

40. Theis F, Miles EA, Nebe-von-Caron G, Powell JR, Hurst TL, Newsholme EA \& Calder PC (2001) Influence of dietary supplementation with long-chain $n-3$ or $n-6$ polyunsaturated fatty acids on blood inflammatory cell populations and functions and on plasma soluble adhesion molecules in healthy adults. Lipids 36, 1183-1193.

41. Hwang D (1989) Essential fatty acids and immune response. FASEB J 3, 2052-2061.

42. Khan WA, Blobe GC \& Hannun YA (1995) Arachidonic acid and free fatty acids as second messengers and the role of protein kinase C. Cell Signal 7, 171-184.

43. Calder PC, Bond JA, Harvey DJ, Gordon S \& Newsholme EA (1990) Uptake and incorporation of saturated and unsaturated fatty acids into macrophage lipids and their effect upon macrophage adhesion and phagocytosis. Biochem $J$ 269, 807-814. 
44. Montero D, Kalinowski T, Obach A, Robaina A, Tort L, Caballero MJ \& Izquierdo MS (2003) Vegetable lipid sources for gilthead sea bream (Sparus aurata): effects on fish health. Aquaculture 225, 353-370.

45. Bell JG, Dick JR \& Sargent JR (1993) Effect of diets rich in linoleic or $\alpha$-linolenic acid on phospholipid fatty acid composition and eicosanoid production in Atlantic salmon (Salmo salar). Lipids 28, 819-826.

46. Bell JG, Farndale BM, Dick JR \& Sargent JR (1996) Modification of membrane fatty acid composition, eicosanoid production, and phospholipase A activity in Atlantic salmon
(Salmo salar) gill and kidney by dietary lipid. Lipids 31, $1163-1171$

47. Leray C, Nonnotte G \& Nonnotte L (1986) The effect of dietary lipids on the trout erythrocyte membrane. Fish Physiol Biochem 1, 27-35.

48. Johnston DV \& Marshall LA (1984) Dietary fat, prostaglandins and the immune response. Prog Food Nutr Sci 8, 3-25.

49. Farndale BM, Bell JG, Bruce MP, Bromage NR, Oyen F, Zanuy S \& Sargent JR (1999) Dietary lipid composition affects blood leucocyte fatty acid compositions and plasma eicosanoid concentrations in European sea bass (Dicentrarchus labrax). Aquaculture 179, 335-350. 